\title{
NOTIFICATIONS OF Q FEVER IN NEW SOUTH WALES, 1991-2000
}

\author{
Ming Lin, Valerie Delpech, and Jeremy McAnulty \\ Communicable Diseases Surveillance and Control Unit \\ NSW Department of Health
}

\section{Sue Campbell-Lloyd \\ Immunisation Unit}

NSW Department of Health

Zoonoses are diseases in humans that are acquired from an animal source. Although there are more than 60 recognised zoonoses in Australia, ${ }^{1}$ brucellosis, leptospirosis and Q fever present the greatest potential for epidemics and pose the greatest occupational risk. These diseases are notifiable in New South Wales. Q fever is the most frequently-notified zoonotic infection in Australia, and about 500 cases are reported nationally every year. $^{2}$

\section{Q FEVER}

$\mathrm{Q}$ fever is a rickettsial illness caused by Coxiella burnetii. Sheep, cattle, goats, cats, dogs, some wild animals (such as bandicoots and many species of feral rodents), birds, and ticks are natural reservoirs for the virus. In humans, the illness has an incubation period of two to three weeks, and the onset of illness is characterised by fever, headache, weakness, malaise and severe sweats. ${ }^{3}$

Outbreaks of Q fever have occurred in occupational groups who work with animals that are reservoirs for the disease, including stockyard workers, meat packing and rendering workers, abattoir and dairy workers, and medical and veterinary research workers. Transmission is usually through airborne dissemination of the organism in dust particles, but can also occur through direct contact with contaminated material, or the ingestion of contaminated placentas or milk. Ticks may also be involved in the transmission of the organism. Cases have occurred in individuals who have had no direct contact with contaminated animals or their bodily fluids, but who have been downwind from sources of contamination. ${ }^{3-7}$

\section{METHODS}

Under the NSW Public Health Act 1991, all laboratories must notify presumptive and confirmed cases of $\mathrm{Q}$ fever to their local public health units (PHUs). PHU staff record the details on a confidential statewide database, the Notifiable Disease Database (NDD).

Data for this review were extracted from NDD for the period January 1991 to December 2000. We analysed the characteristics of notified cases for age, sex, area health service of residence, occupation, and date of onset. Annual age-specific notification rates were calculated using the mid-year estimated population for NSW from the Australian Bureau of Statistics for each year.

\section{RESULTS}

During the 10 year period 1991-2000, a total of 2351 notifications of Q fever were reported in NSW, with an average annual notification rate of 3.8 cases per 100,000 population. The annual rate varied from a peak of 6.7 per 100,000 population in 1996 to 1.8 per 100,000 population in 2000 (Table 1, Figure 1).

Males accounted for 84.1 per cent of all the notifications, and the male to female ratio was 5.7:1 (Table 1). The highest age-specific notification rates were 12.1 per 100,000 for males in the 20-24 year age group, and 2.2 per 100,000 for females the 35-39 age group (Figure 2).

A total of 34 cases (1.5 per cent) occurred among children under five years of age, with an age-specific notification rate of 1.5 per 100,000 population. Most of these cases occurred in children aged one year or less ( 32 cases) with a male to female ratio of 4.6:1. All 32 cases were reported from one of nine rural area health services (except for one infant whose residential details were missing).

\section{TABLE 1}

NOTIFICATIONS OF Q FEVER BY SEX AND AREA HEALTH SERVICES, NSW, 1991-2000

\begin{tabular}{|lrrr|}
\hline Area Health Service & MALES & FEMALES & TOTAL* \\
\hline Central Sydney & 13 & 2 & 15 \\
Northern Sydney & 7 & 1 & 8 \\
Western Sydney & 22 & 5 & 27 \\
Wentworth AHS & 9 & 1 & 10 \\
South Western Sydney & 9 & 6 & 15 \\
Central Coast & 13 & 0 & 13 \\
Hunter & 109 & 19 & 129 \\
Illawarra & 19 & 0 & 21 \\
South Eastern Sydney & 13 & 2 & 16 \\
Northern Rivers & 228 & 45 & 273 \\
Mid North Coast & 265 & 66 & 348 \\
New England & 419 & 77 & 496 \\
Macquarie & 366 & 47 & 414 \\
Mid Western & 119 & 11 & 131 \\
Far West & 145 & 28 & 174 \\
Greater Murray & 70 & 7 & 79 \\
Southern & 102 & 24 & 126 \\
Not Stated & 19 & 1 & 20 \\
NSW & 1947 & 342 & 2315 \\
\hline *Includes cases whose gender was unknown. & \\
& & & \\
\hline
\end{tabular}




\section{FIGURE 1}

NOTIFICATION RATES OF Q FEVER BY YEAR AND MONTH, NSW, 1991-2000

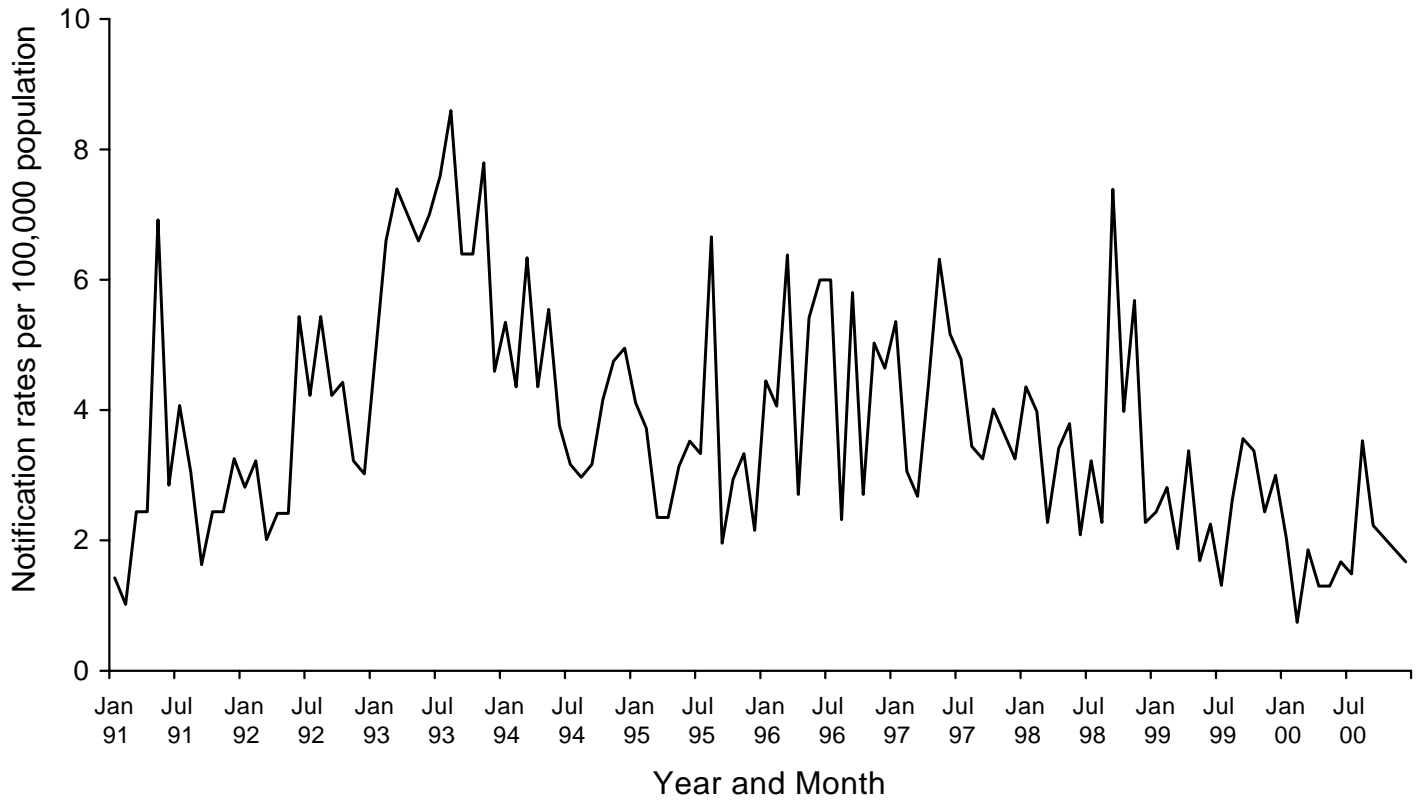

\section{FIGURE 2}

NOTIFICATION RATES OF Q FEVER BY AGE GROUPS, NSW, 1991-2000

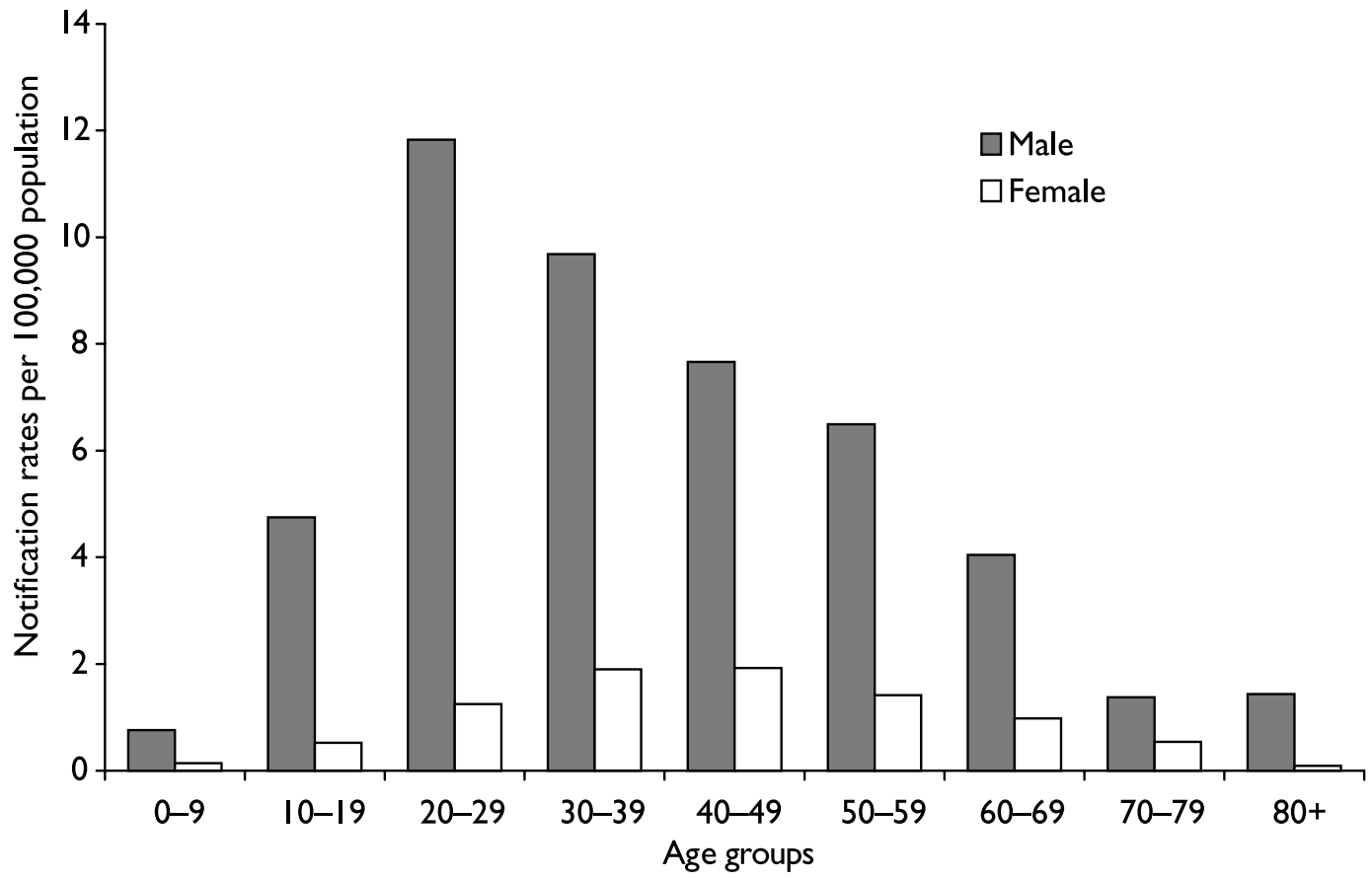




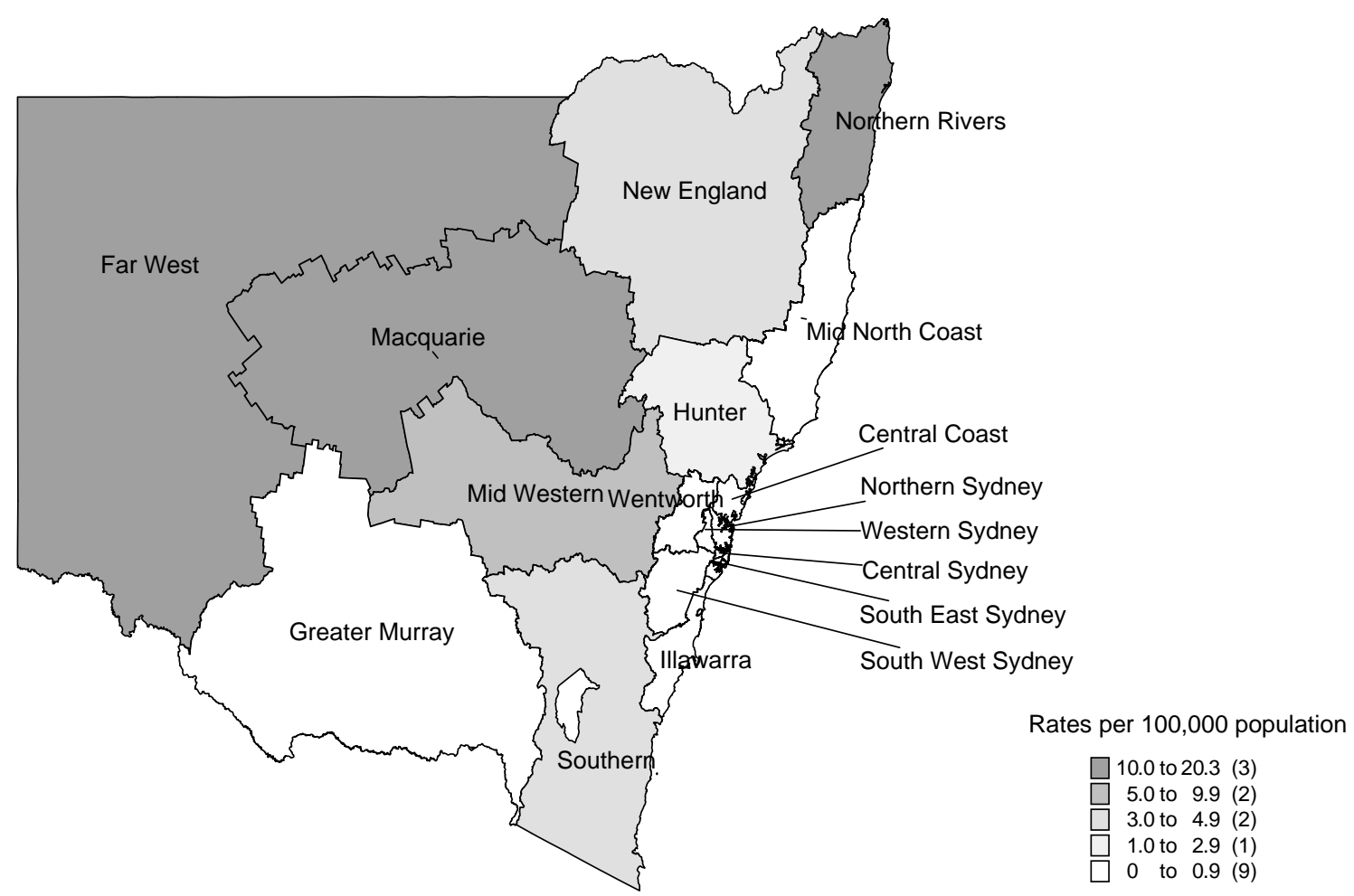

New England, Macquarie and Mid North Coast area health services accounted for 21.4 per cent, 17.9 per cent and 15.0 per cent of all the cases respectively. The highest notification rates of disease by area health service were Macquarie (40.3 per 100,000), Far West (34.5 per 100,000) and New England (27.5 per 100,000) (Figure 3, Table 1).

Occupational information was provided for 1526 (66 per cent) notifications. Among these, the most frequently reported occupations were animal-related occupations such as abattoir or meat workers (51.4 per cent); and agriculture related occupations, such as farmers, shearers and dairy farmers (29 per cent). Notifications among abattoir and other animal-related workers have decreased significantly from a peak of 123 cases (30.4 per cent of the total annual notifications) in 1993 to 13 cases (13.5 per cent) in 2000. In contrast, notifications for farmers and other agricultural-related occupations remained steady from 25 cases ( 7.5 per cent) in 1993 to 26 cases (27.1 per cent) in 2000 .

\section{DISCUSSION}

Like other zoonoses, Q fever can produce non-specific clinical signs and symptoms. Therefore, a definitive diagnosis depends on appropriate laboratory investigation. It is estimated that only about 50 per cent of cases of Q fever were diagnosed by health professionals, so the true figure of the disease is likely to be underreported. ${ }^{8-9}$

Q fever notifications reached their lowest level in 2000, with a rate of 1.8 per 100,000 population. Q fever has a strong association with particular occupational groups such as abattoir workers. Immunisation against $\mathrm{Q}$ fever has been available in Australia since 1989, and provides an effective prevention for high risk occupations. Notifications have particularly decreased among abattoir workers, which may be due to the introduction of effective immunisation. In 2000, the Commonwealth Minister for Health and Aged Care has announced a National Q Fever Management Program to be conducted over three years. The Program will commence in NSW in 2001 and will provide immunisation for abattoir workers, those closely associated with the meat processing industry, and shearers.

\section{CONCLUSION}

Surveillance of Q fever is vital to help monitor its incidence and the effectiveness of prevention programs such as immunisation. Public health units are encouraged 
to collect detailed case risk data (most importantly, occupation). Changes in risk factors over time can then be evaluated to ensure immunisation is targeted at those most at risk of the disease.

\section{REFERENCES}

1. Stevenson WJ \& Hughes KL. Synopsis of zoonoses in Australia, 1995, vii. Canberra: AGPS, 1998.

2. Thomson J, Lin M, Halliday L, Preston G, McIntyre P, Gidding H, et al. Australia's notifiable diseases status, 1998. Comm Dis Intell 1999; 23: 277-305.

3. Chin J (editor). Control of Communicable Diseases Manual. 17th edition. Washington, DC: American Public Health Association, 2000.
4. Garner MG, Longbottom HM, Cannon RM et al. A review of Q fever in Australia 1991-1994. Aust N Z J Public Health 1997; 21: 722-30.

5. Q fever outbreak in an abattoir in Cooma, NSW. Commun Dis Intell 1998; 22: 222.

6. Maurin M, Raoult D. Q fever. Clinical Microbiology Reviews 1999; 12(4): 518-53.

7. Serbezov VS, Kazar J, Novkirishki V, Gatcheva N, Kovacova E, Voynova V. Q fever in Bulgaria and Slovakia. Emerg Infect Dis 1999; 5(3): 388-94.

8. Raoult D, Marrie T. Q fever. Clin Infect Dis 1995; 20: 489_ 496.

9. Casolin A. Q fever in New South Wales Department of Agriculture workers. J Occup Environ Med 1999; 41: 2738. $\mathbf{F}$

\section{COMMUNICABLE DISEASES, NSW: JUNE 2001}

\section{TRENDS}

Analysis of notifications of persons with communicable diseases through to April 2001 (Table 2, Figure 1) indicates that both arboviral and salmonella infections began their expected declines with the onset of cooler weather. The notable exception to this trend was the Hunter Area Health Service, which experienced an increase in Ross River virus infection notifications in April. Notifications of pertussis also declined markedly to baseline levels from the threeyear peak in mid-2000. Conversely, notifications of gonorrhoea have remained high among men in South Eastern Sydney.

\section{NSW INFLUENZA SURVEILLANCE}

The NSW Influenza Surveillance Program commenced in the first week of May. This enhanced surveillance program runs from May to October each year. Data sources for 2001 include:

- clinical reports of influenza-like illness (ILI) by NSW general practitioners (GPs) from the Australian Sentinel Practice Research Network (ASPRN), as well as three area health services (Southern, Northern Sydney and New England);

- virological and serological reports of influenza, parainfluenza, adenovirus, rhinovirus and respiratory syncytial virus (RSV) by six major public laboratories: South Eastern Area Laboratory (SEALS), Institute of
Clinical Pathology and Medical Research (ICPMR), South Western Area Pathology Service, Pacific Laboratory Medicine Services, Hunter Area Pathology Service, and the New Children's Hospital Laboratory;

- the Directed Virological Surveillance (DVS) scheme that involves 32 general practioners-from four metropolitan and 5 rural area health services-who submit samples from patients with ILI for viral testing at SEALS and ICPMR;

- information on international influenza activity, which is regularly updated from the World Health Organization's FluNet.

In the week ending May 4, 2001, four laboratory diagnoses of influenza were reported: two influenza A and two influenza B infections. Sentinel GPs reported some levels of activity of ILI in NSW. In April 2001, little influenza activity had been reported from elsewhere in the Southern Hemisphere.

\section{ARBOVIRUS ACTIVITY}

Data from the NSW Arbovirus Surveillance and Mosquito Monitoring Program indicate that after March Kunjin and Murray Valley encephalitis viruses were no longer active in western NSW (Table 1). The decline in flavivirus activity followed a general drop in mosquito numbers across inland NSW. No acute human cases of either of these infections have been reported in NSW during 2001. Reports of 